E.L.U.A. 3, 1985-1986, págs. 149-163

\title{
LA ESTRUCTURA FONOLÓGICA DE LA LENGUA CHINA: INTRODUCCIÓN AL ESTUDIO DE LOS TONOS
}

\author{
TACIANA FISAC
}

1. Uno de cada cuatro habitantes del mundo habla y utiliza el chino, una lengua cuyos ideogramas han pervivido sin descomponerse desde hace tres mil años. Por el contrario se han desarrollado, y han evolucionado a partir de un sistema básico. En China existen numerosos dialectos, pero la lengua oficial, tanto hablada como escrita, es el putonghua普通话, que podríamos traducir como lengua co-

mún. El putonghua se fundamenta en el llamado dialecto del norte o perkinés, sobre todo en lo que atañe a la fijación de su correcta pronunciacion. Es la lengua cuyo modelo se utiliza a lo largo de todo el país, tanto en los organismos oficiales como en los medios masivos de comunicación o en la creacion literaria. Aunque hay numerosas diferencias fonológicas y tonales entre todos y cada uno de los dialectos, al referirnos a la lengua china tomaremos como referencia la lengua oficial o lengua común.

2. El idioma chino escrito está formado por caracteres ideográficos o ideogramas. Se trata de una grafía simbólica de origen muy diverso, frecuentemente pictográfico, aunque también abstracto. Progresivamente, con la combinación de pictogramas e ideogramas sencillos, se fueron introduciendo otros complejos que añadidos a compuestos fonéticos, a préstamos falsos, y junto con grafías de extensión etimológica, dieron lugar a los caracteres modernos. Las combinaciones son múltiples. Una muestra de ello es la obra que se realizó por 
orden del emperador Kang Xi (1662-1723), un diccionario que tuvo cuarenta y dos volúmenes y en el cual se recogían más de 47.000 caracteres.

Los ideogramas pueden descomponerse principalmente en dos partes: una de ellas expresa el significado (radical) y otra el sonido (elemento fonético). Ahora bien, tanto la referida al significado como la que atiende a la grafía fónica son simplemente indicativas del modo en que ha de leerse el carácter. Así por ejemplo 包, bao es considerada una grafía fónica que unida a los distintos radicales adquirirá diversas acepciones. Veamos los siguientes ejemplos:

$$
\begin{aligned}
& \text { bão 包 (paquete); báo雹 (granizo) } \\
& \text { băo 饱 (harto); bào 抱 (abrazar) }
\end{aligned}
$$

La formación de los nuevos caracteres se produjo, en muchos casos, mediante la convergencia de dos procesos. De un lado, el mantenimiento de familias fonéticas; de otro, el aditamento de nuevos radicales a los ideogramas de carácter homófono. Sin embargo, debido a cambios de la expresión escrita de los caracteres, así como a variaciones fonéticas, o incluso a errores en su utilización, un gran número de ellos han sufrido alteraciones ajenas a las pautas de las mencionadas combinaciones. Asi por ejemplo el elemento fonético I gong, se convierte en jiāng 江 (rio), jiãng 豆工 (una especie de fréjol) y varía de nuevo en hóng 虹 (arco iris) y en hóng 㬎 (rojo).

3. Una de las peculiaridades de tan complicado idioma es que a cada ideograma corresponde un sonido con un tono determinado. En el chino, la relación entre el carácter, la pronunciación y sobre todo el tono, responde a un principio de organización arbitrario y complejo. Es necesario memorizar cada una de las distintas formas fónicas existentes. Se podría hablar de una relación pictofonética entre el carácter y su pronunciación, pero no así entre el carácter y el tono ${ }^{1}$.

El tono es una de las características más importantes de la lengua china. El tono refiere a una cualidad acústica, produce variaciones en la altura de los sonidos que dan lugar a una fonología musical. Ello

1 A propósito del rasgo suprasegmental tonal, véase, para una visión general, A. S. Abramson, 1961; E. Alarcos Llorach, 1967, 1974; A. di Cristo, 1975; G. Faure, 1964, 1973; V. M. du Feu, 1970; D. J. Hirst, 1976, 1980; R. Jakobson y M. Halle, 1973; Ph. Lieberman, 1967; B. Malmberg, 1971; A. Martinet, 1971; Z. Muljacic, 1974 y N. Trubetzkoy, 1976, entre otros. Con relación directa al problema del tono en la lengua china, véase $H$. Wong, 1953. 
ocurre a causa de la frecuencia o número de vibraciones por segundo de los sonidos, de ahí que el tono varie según las veces que se repite en cada unidad de tiempo el ciclo completo de la onda. Resultará un sonido más agudo cuanto mayor sea el número de vibraciones (Lamíquiz, 1983: 204). Los tonos se caracterizan por un rasgo de la curva melódica y al igual que los fonemas, tienen una función distintiva (Martinet, 1975: 320). En la lengua china, el tono produce una sonoridad particularmente melódica. Podriamos representarlos con la notación musical (Mateos, 1977: XIII) del siguiente modo:

Primer tono:

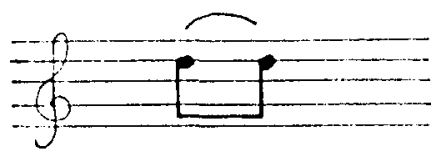

Segundo tono:

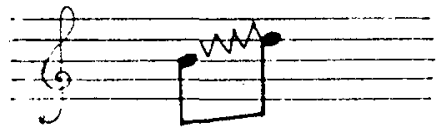

Tercer tono:

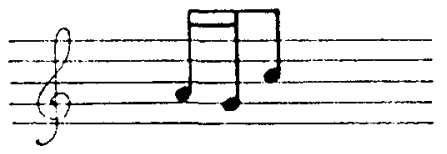

Cuarto tono:

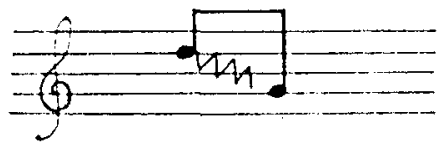

Esta estructura musical del idioma chino es tan importante como las vocales y consonantes porque constituye un fonema segmental (Chao, 1977: 59). El tono modifica el sentido de la palabra. Por ejemplo, el término ma, con cada uno de los tonos, adquirirá distintos significados. Asi:

$$
\begin{aligned}
& \text { mã 婳 (madre) } \\
& \text { má 床 (cáñamo) } \\
& \text { mà 墨 (caballo) } \\
& \text { mà 駡 (regañar) }
\end{aligned}
$$

3.1. Los tonos básicos del putonghua son cuatro: ping 平, shang 
上, qu 去, ru $入$. Empero no estuvieron claramente diferenciados durante muchos siglos, pese a ser utilizados en el habla. Los primeros testimonios sobre el tono se remontan a la dinastía del emperador Yong Ming (483 d. C.), cuando el budismo se extendia por toda China. Varios escritores y estudiosos como Zhou Yong. Shen Yue, Xie Yao y Wang Rong se interesaron por su diferenciación al afrontar la traducción de los Sutras. Éstos recogían comentarios sobre los vedas o libros sagrados del budismo, que pronto fueron incorporados al acervo cultural y religioso de la China clásica. Por ello se hacía necesario imitar el sonido melódico que producía la lectura de aquellos escritos en su lengua vernácula. Es asi como eruditos de aquel tiempo tuvieron que indagar con detenimiento la manera de mantener su carácter musical al traducirlos al idioma chino.

En la obra Comentarios del maestro Zhou Yong, éste explica cómo él fue el primero en diferenciar los tonos y en averiguar la forma correcta de traducirlos. Por su parte, Shen Yue registra cómo antes de él los estudiosos y poetas no distinguían los tonos: «Fui capaz de entender estas cuestiones y aprender e interpretar los misterios de las letras" (Huang, 1955: 10).

Asimismo, a lo largo del siglo $V$ a $C$., durante el reinado del emperador Yong Ming, el príncipe Zi Liang reunió en la Ciudad Prohibida de Pekín a numerosos especialistas y monjes, con el propósito de crear un instituto para el estudio de la fonética en la traducción de los Sutras. Estamos, sin duda, ante lo que supuso un paso importante para la consolidación de la lengua y posterior florecimiento de la literatura china.

Otro momento importante para la clasificación tonal de la lengua china se produjo durante la dinastía Tang (618-907). Es quizás ésta una de las épocas de mayor auge de la poesía. En ella aparecen personalidades como Li Bai o Du Fu que de manera tan admirable han descrito sentimientos, naturaleza y secuencias vitales magistralmente imbricados con la propia experiencia personal. De ahí que las reglas de versificación y la utilización de los tonos aparezcan ya sólidamente fijados en la creación poética, en la búsqueda de un óptimo ajuste melódico. Un libro de esta dinastía explicaba así las características de los tonos: "el tono llano es triste y tranquilo; el ascendente, serio y ascenciente; el tono tercero es sereno, claro y lejano, y el descendente es recto, directo y apremiante» (Huang, 1955: 10). Efectivamente el primer tono siempre es descrito como el más uniforme y llano. El segundo como un tono alto-ascendente.

Durante la dinastía Ming (1368-1642), el monje Zhen Kong, escribió un libro titulado El cantar de la llave de Jade en el cual explicaba de la 
siguiente manera cómo debían pronunciarse los tonos: «el llano léelo liso, sin altibajos; el segundo más fuerte y con brío; el tercero, claro y dejando que se aleje; y el cuarto, corto, rápido y terminando con premura" (Ibidem, 11). En el tercer tono, el más largo de todos, se produce una suerte de descenso y de ascenso de la altura y por eso muchas veces se percibe como un sonido cuya cadencia tiende a distanciarlo.

Un manual de fonética, de la dinastía Qing (1644-1912) dice así: "el tono primero es el más largo; el segundo y el tercero son algo más cortos, y el cuarto infinitamente más corto y sin cola. Los más fuertes y rápidos son el segundo, tercero y cuarto. El primero es el más largo y más pausado". El cuarto tono destacará siempre por su sequedad expresiva y lo efímero y breve de su condición. Es también el más fuerte e impetuoso. De esta misma dinastía es un Libro sobre la pronunciación escrito por Jiang Yong. Asemeja el primer tono al sonido del tambor, por ser el más largo; y los sonidos del segundo, tercer y cuarto tono al sonido del golpear la madera, el barro o la piedra, por ser más cortos y fuertes. Su descripción es más estética que real, ya que sólo distingue, aunque de forma acertada, el tono primero.

3.2. Los cuatro tonos: ping 平, shang 上, qu去, ru $入$, ya eran diferenciados en la dinastía del Norte y del Sur (420-589 d. C.). Posteriormente, las consonantes iniciales sordas se convirtieron en tono yin $\beta$ 月 y las consonantes sonoras en tono yang $\beta_{日}$ (Chao, 1977: 59). De esta forma, los cuatro tonos dieron lugar a ocho. De ello da cuenta el fonema shi:

$\begin{array}{ll}\text { yinping } & \text { : shi 诗 (poeta) } \\ \text { yangping } & : \text { shi 时 (tiempo) } \\ \text { yinshang } & : \text { shi 便 (enviar) } \\ \text { yangshang } & : \text { shi 是 (ser) } \\ \text { yinqu } & : \text { shi 试 (ensayar) } \\ \text { yangqu } & : \text { shi 事 (asunto) } \\ \text { yinru } & : \text { shi 识 (saber) } \\ \text { yangru } & : \text { shi 会 (alimento) }\end{array}$


3.3. En la creación poética se hará una clara distinción de los dos grupos importantes. Unos serán los tonos uniformes: ping 平; y otros los tonos oblicuos: shang 上, qu去, ru $\lambda$. A los primeros pertene-

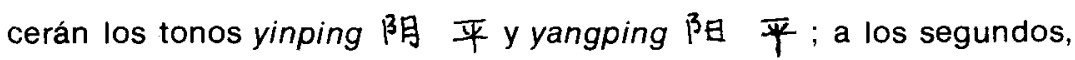
todas las variaciones de los tonos shang上, $q u$ 去 y ru $\lambda$. Utilizaremos el signo $X$ para representar a los del primer grupo y el signo $O$ para los del segundo, así como el signo * para indicar rima. Este puede ser ejemplo de una poesía donde se fija la posición de los tonos:

$\begin{array}{lllllllllll}x & x & 0 & 0 & x & 0 & 0 & x & x & 0 \\ 0 & 0 & 0 & x & x & x & x & x & 0 & 0 \\ x & x & 0 & 0 & x & 0 & 0 & x & x & 0 & * \\ 0 & 0 & 0 & x & x & x & x & x & 0 & 0\end{array}$

Una poesía del famoso Du Fu (712-770) se guía por el citado esquema (Yu, 1981: 181). En ella encontramos la conjunción de elementos melódicos, como el tono; poéticos, por la misma naturaleza expresiva de los versos; y estéticos ya que la propia caligrafía china es un discurso plástico y un medio privilegiado para el arte poético (Fenollosa, 1983: 24).

\begin{tabular}{|c|c|c|c|c|c|c|c|c|c|}
\hline$\underset{x i}{4}$ & $\frac{\text { 草 }}{\text { cdo }}$ & $\begin{array}{l}\text { 微 } \\
\text { wei }\end{array}$ & 闽 & $\begin{array}{l}\text { 岸 } \\
a \text { an }\end{array}$ & 危 & $\begin{array}{l}\text { 木昶 } \\
\text { giang }\end{array}$ & $\begin{array}{l}\text { 㯰 } \\
d u ̈\end{array}$ & $\begin{array}{l}\text { 夜 } \\
\text { yiè }\end{array}$ & $\begin{array}{l}\text { 舟. } \\
z h o \bar{u}\end{array}$ \\
\hline 星 & $\frac{\text { 垂 }}{\text { chui }}$ & $\begin{array}{c}\text { 平 } \\
\text { ping }\end{array}$ & $\begin{array}{l}\frac{\text { 里予 }}{y e} \\
y \tilde{e}\end{array}$ & $\begin{array}{l}\text { 榈了, } \\
\text { kuo }\end{array}$ & $\underset{y u \dot{e}}{\text { 月 }}$ & $\begin{array}{c}\text { 湑 } \\
\text { yóng }\end{array}$ & $\underset{d \hat{a}}{大}$ & $\sum_{\text {irang }}$ & $\begin{array}{l}\text { 流。 } \\
\text { liu }\end{array}$ \\
\hline $\begin{array}{c}\text { 名 } \\
\text { ming }\end{array}$ & $\frac{\text { 崖 }}{q i}$ & $\underset{\text { wén }}{\bar{x}}$ & $\begin{array}{c}\text { 草 } \\
\text { cão }\end{array}$ & $\begin{array}{l}\text { 著， } \\
\text { zhú }\end{array}$ & $\underset{\text { guãn }}{\text { 官 }}$ & $\begin{array}{l}\text { 僬 } \\
\text { ying }\end{array}$ & $\begin{array}{l}\text { t⿱ } \\
\text { là }\end{array}$ & $\begin{array}{l}\text { 病 } \\
\text { bing }\end{array}$ & 休! \\
\hline $\begin{array}{l}\text { 票固 } \\
\text { pião }\end{array}$ & $\sum_{z h i}$ & $\begin{array}{l}\text { 何 } \\
\text { hé }\end{array}$ & $\begin{array}{l}\text { 所 } \\
\text { süo }\end{array}$ & si & $\begin{array}{c}\text { 天 } \\
\text { tiần }\end{array}$ & $\begin{array}{c}\text { 土也 } \\
d i\end{array}$ & $\overline{y i}$ & $\begin{array}{l}\text { 垱 } \\
\text { shā }\end{array}$ & $\frac{\sqrt{S g}}{O U}$ \\
\hline
\end{tabular}

Es ya conocida la importancia del componente fonético en la poesía (García Berrio 1977: 241). Ahora bien, en el arte poético chino, el ritmo y la melodía adquieren un carácter decisivo. El elemento fónico es aún más primordial y abre un abanico de posibilidades mucho mayor que en cualquier lengua de Occidente, a causa de su riqueza tonal y su versatilidad musical. Por eso, si toda poesía es de difícil traducción a otro idioma, en el caso del chino, la complejidad se multiplica. 
3.4. Los ocho tonos antiguos se modificaron y absorvieron de la siguiente forma en los cuatro tonos de la lengua común (Beijing daxue zhongwenxi, 1964: 15):

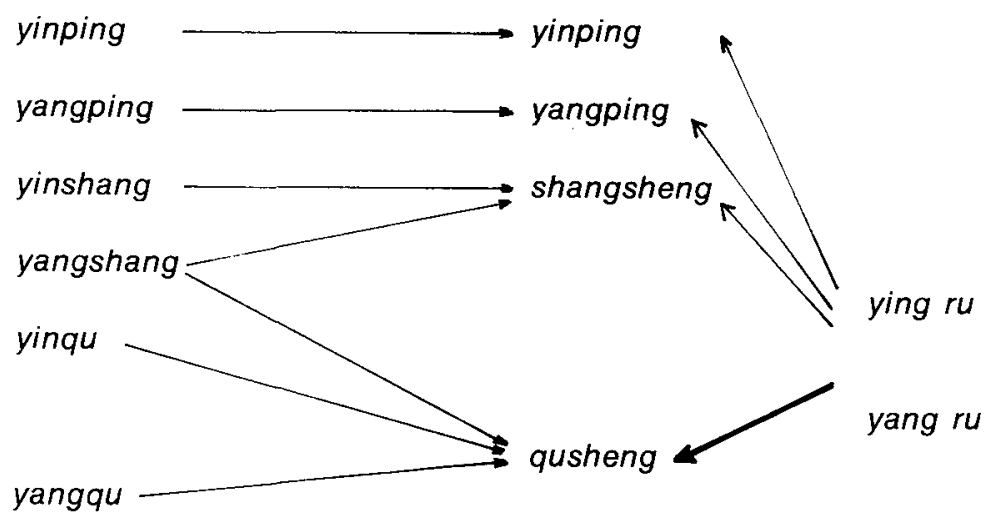

Los cambios tonales, perceptibles en los distintos dialectos actuales, engloban estos ocho tonos. Aunque cualquiera de dichos dialectos carece de uno o varios tonos, en el putonghua o lenguaje común se han conservado estos cuatro:

Primer tono: yinping $\quad$ 月平 alto-llano o alto-sostenido

Segundo tono: yangping $\bar{B}$ 平 alto-ascendente

Tercer tono: shangsheng 上声 descendente-ascendente

Cuarto tono: qusheng $夫$ 声 descendente

Para distinguir los cuatro tonos se utilizan, en la transcripción escrita de la fonética, unos signos sobre la vocal principal de cada sílaba:

En el chino moderno estos son los cuatro tonos:

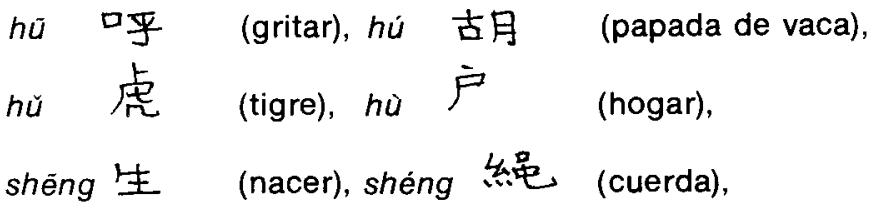




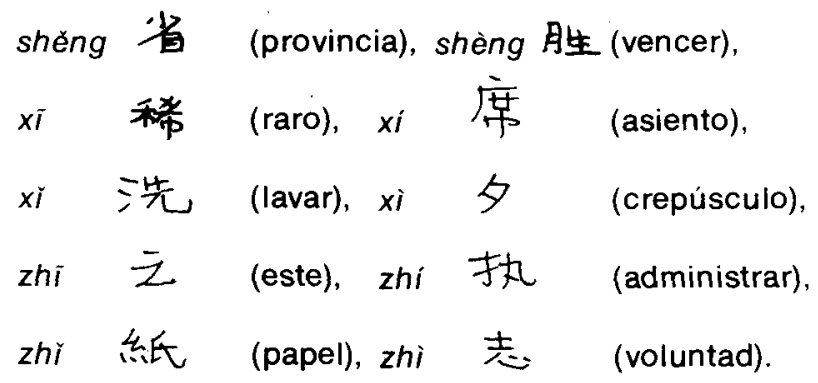

3.5. Al unir dos sílabas, en el uso cotidiano del lenguaje, se producen algunos cambios en el tono. La primera sílaba sufre variaciones, sobre todo cuando es de tono shangsheng 上声 (tercer tono), así como en los casos de ciertas palabras: yi - (uno, una, un) y bù J-(no). Son reglas que se utilizan comúnmente en la lengua hablada, aunque no se distinguen en la transcripción fonética.

Cuando al tono shangsheng 上声, es decir el tercer tono, le sucede otro que no sea shangsheng 上声, entonces la inflexión del sonido es menos ondulante y se pronuncia de modo sólo descendente, sin su ascendencia final. Podriamos denominarlo tono semitercero:

$$
\begin{aligned}
& \text { Bèijing 北京(Pekín) } \\
& \text { zhŭxi 主席 (presidente) } \\
& \text { lăoshi 老 师 (profesor) } \\
& \text { zhŭnbei准 借 (preparar) }
\end{aligned}
$$

Cuando aparecen dos palabras consecutivas de tercer tono, la primera se convierte en tono yangping $\beta$ E $\bar{F}$ (segundo tono).

$$
\begin{aligned}
& \text { håshuì } \rightarrow \text { haishur 海 水 (agua de mar) }
\end{aligned}
$$

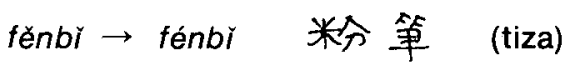

Una misma sílaba, al encontrarse acompañada de otra de distinto tono y significado, puede sufrir diversos cambios tonales: 
fãqr 发起 (iniciar) qrichũ 走已 初 (al principio)

qicao 走已草 (hacer un borrador)

dàhài 大 海 (océano) hăiyàn 海 燕 (golondrina)

haishur 海 水 (agua de mar)

Por otra parte, la palabra $y i$ - (uno, un, una) se lee en el tono yinping 阴平 (primer tono), pero cuando precede a otra silaba de tono yinping $\beta$ 月 平 (primer tono), yangping $\beta$ 日 平 (segundo tono) 0 shangsheng 上声 (tercer tono), entonces se pronuncia en tono qusheng去声(cuarto tono) (Universidad de Pekin, 1963: 130). Por ejemplo:

$$
\begin{aligned}
& \text { yìtiān } \rightarrow \text { yitiain }-天 \text { (un dia) } \\
& \text { yinian } \rightarrow \text { yinian - 年 (un año) }
\end{aligned}
$$

Del mismo modo, la palabra yi - (uno, una, un) cuando precede a otra de tono qusheng 去声 (cuarto tono), se convierte en yangping 阳平 (segundo tono). Este es el caso de:

$$
\begin{aligned}
& \text { yĩyè } \rightarrow \text { yiyè 一 夜 (una noche) } \\
& \text { yĩdui } \rightarrow \text { yidui }-\beta \quad \text { (una tropa) } \\
& \text { yïwàn } \rightarrow \text { yíwàn - 万 (diez mil) } \\
& \text { yijyian } \rightarrow \text { yijian - 件 (un "asunto") }
\end{aligned}
$$

El adverbio bu 不 (no) cuando va seguida de otro tono qusheng 去声 (cuarto tono) se convierte en yangping $\beta$ 日 平(segundo tono):

$$
\text { bùhuài } \rightarrow \text { búhuài } \text { ホ. } \pm \text { T. }
$$

En muchas ocasiones al variar el tono de $y i$ 一 (uno) y bu オ.(no) se puede modificar totalmente el significado: 


$$
\begin{aligned}
& \text { yì wàn 一碗 (una taza) yiwãn - 万 (diez mil) } \\
& \text { yì tiáo - 条 (un artículo) yítiáo - 足兆 (un salto) } \\
& \text { yi piãn - 篇 (una «disertación») yĩpian - 片 (una lámina) } \\
& \text { bù xiăng 万、想 (no pensar) búziāng 不像 (no parecerse) } \\
& \text { bù shi T. 时 (a destiempo) búshi T 是 (no ser) }
\end{aligned}
$$

3.6. Cada morfema monosilábico chino tiene su tono definido, pero su extensión semántica no se reduce a un solo sentido, estos últimos son los carácteres menos numerosos. Asi pues, un mismo ideograma homótono puede tener significados tan diversos como en el siguiente ejemplo:

$$
\text { xin 人言 }
$$

Fidelidad; sinceridad; buena fe.

Creer; dar fe a; confiar; tener confianza en; fiarse de.

Fe; creencia; confianza.

Digno de fe: verdadero; verídico; buena ley. De hecho; en efecto.

Hacer fe. Sello; letra de crédito. Fehaciente; fidedigno.

Carta; mensaje; misiva.

Noticia; anuncio.

Mensajero; enviado; encargado de una misión. Ser portador de un mensaje.

Pernoctar dos noches en un lugar.

Dejar plena libertad a. A gusto de; a su gusto.

Que llega en tiempo fijo; estacional; periódico.

(pop) Arsénico.

Apellido.

(Mateos, 1977: 377)

Ya hemos señalado cómo la importancia del tono es tan grande que su variación produce una modificación léxica:

$$
\text { bai 白 blanco bar 百 ciento }
$$

Ahora bien, no sólo distinguen las sílabas homófonas sino que en 
muchas ocasiones perdura la grafía del carácter y se produce, sin embargo, una diferenciación semántica y sintáctica.

Un adjetivo como hăo 女子 cuya acepción en el tercer tono es bueno, cuando se pronuncia en el cuarto tono se transforma en el verbo haò 女子 gustar.

El sustantivo zhão 朝 (la mañana, el día) en el primer tono, se convierte en el verbo zháo 朝 (saludar) en segundo tono.

En las puertas de un templo chino, situado en lo alto de una montaña, se hallaba un gran cartel que decía así:

\section{雲朝朝, 朝朝朝, 朝朝朝散。}

Yún zhão zháo, zhão zhão zháo, zhão zháo zhão sàn. Podriamos traducirlo asi: Las nubes por la mañana vienen a saludar, todos los dias por la mañana saludan, y todos los dias cuando han saludado se marchan. Solamente una correcta ortología nos indica el sentido de esta frase.

En la lengua hablada, y sobre todo en la lectura, es muy común la pronunciación incorrecta de muchas palabras (Rongyi ducuo de zi, 1971) y más aún es el caso de términos que con una misma grafía son homófonos, y homótonos, aún cuando poseen tambien una fonética y una semántica muy diversa. Tal es el caso de:

a) nà (nèi) 那

(pronom. o adj. demostrativo) Ese, esa, eso; aquel, aquella, aquello. (adv.) Así; de esa manera; entonces; allí.

b) nèi

Contracción de 那 nè y de $\bar{i}$ pron. ord. de a).

c) nă

(adv. interrogativo) ¿Cuál?; ¿cómo?; ¿cuándo?; ¿dónde? En expresiones con 也 ye o 都 tu (partic. indefinida) Cualquiera; comoquiera; dondequiera; por doquier.

d) nĕi

b) (contracción de 月阝 nă y de $\bar{i}$ ) pron. pop. de c).

e) na

Partíc. final, empleada por 啊 (阿) a, después de una 
sílaba que termina con el sonido $N$. Exclamación de sorpresa.

f) núo

Numeroso; mucho.

Tranquilo; apacible.

Contracción fon. de 奈何 naì hé ¿Qué hacer?

讲 núo Desplazar; remover; moverse.

刺那 cha nuo (sánscr. ksana) Un instante; un momento.

g) nùo

(ant.) Partíc. final eufónica o para expresar sorpresa.

奈 nal, 无 那 $\bar{w} \bar{u}$ nuo Imposible; irremediable.

h) $n \bar{a}$

Apellido.

(Mateos, 1977: 674)

4. En el idioma chino no existen los acentos, y tradicionalmente se consideran los cuatro tonos que hemos analizado como los principales (Yuwen jichu zhishi, 1984: 10). Sin embargo hay uno más que también produce modificaciones importantes. Es el tono neutro o tono ligero, que se reconoce ya que sobre la sílaba no se escribe ninguno de los signos $-, \quad, \quad \vee, \backslash$.

El tono neutro aparece en una diversidad de casos, tanto en palabras auxiliares de talante (ba吧, ma孯, ne尼, $a$ 啊), como en las que desempeñan una función en la estructura gramatical (de 的, di土也de 得), o las que realizan funciones gramaticales de modificación del tiempo del verbo, (le 3, kuo 过, zhe 着). Del mismo modo, en sufijos que van detrás de un nombre o pronombre (men 们, zi子, tou 头) o en la segunda sílaba del verbo cuando se repite (kànkan 看看 (ver), shũoshuo 说 说 (hablar)). También es notorio en términos que indican dirección detrás de un verbo, por ejemplo: 
nalai 拿未 (coger y traer), guòlai 过 未 (pasar hacia aquí).

Se utiliza igualmente tras vocablos que indican el lugar detrás de un sustantivo, tales como: shang 上 (arriba), xia 下 (abajo), li 里 (dentro): wùli 屋里 (en casa, dentro de casa). Y del mismo modo ocurre con algunos sufijos cuando van detrás del verbo: wo 我 (me), ni 你 (te), ta 他 (se).

Hay además muchas palabras compuestas en las que la segunda sílaba se convierte en tono neutro, como por ejemplo: jintian 今天 (hoy) difang 土也 $\overline{\bar{J}}$ (lugar). Diferenciar claramente el tono neutro puede ser de una gran importancia, ya que produce una variación total en el significado. Este sería el caso de: măi mai 買费 (comprar y vender), y măimai 買事 (hacer negocios).

En términos generales, la mayoría de las palabras compuestas, cambian la segunda sílaba en un tono neutro, pero en los nombres científicos y en los neologismos no se transforma sino que se conserva el tono original.

5. El tono es, pues, una de las características distintivas de la lengua china. Toda lengua es un sistema simbólico portador de una peculiar cosmología (Galtung, 1983). La aprehensión del mundo circundante se halla condicionada, que no determinada, por el idioma a través de cuyo universo semiótico hemos sido educados. La capacidad del chino para la aprehensión del entorno es prodigiosa. A su riqueza lingüística y fonética une una dosis importante de versatilidad, que se recrea en la elocuente musicalidad de los tonos. Es una melodía, como el propio idioma chino, ambigua. Ambigua como la esencia misma de una cultura milenaria.

\section{Referencias bibliográficas}

Abramson, A. S. (1961), «Identification and discrimination of phonemic tones", en Journal of Acoustical Society of America, 33, pp. 842 y ss. 
Alarcos Llorach, E. (1967), “Los rasgos prosódicos", en: Problemas y principios del estructuralismo lingüistico, Madrid, C.S.I.C., pp. $1-8$.

- (1974), Fonología española, Madrid, Gredos.

Beijing jiaoyu xueyuan shifan jiaoyanshi (1984), Yuwen jichu zhishi, Beijing chubanshe, Beijing.

Cristo, A. di (1975), Xoixante et dix ans de recherches en prosodie, Université de Provence.

Chao, Yuen Ren (1977), Iniciación a la lingüistica, Ediciones Cátedra, Madrid.

Faure, G. (1964), “Aspects et fonctions linguistiques des variations mélodiques dans la chaîne parlée", en: Proceedings of the 9th international Congress of Linguists, The Hague, Mouton, pp. 72-77.

- (1973), «Tendences et perspectives de la recherche intologique», en: Bulletin d'Audiophonologie, 3, pp. 5-29.

Fenollosa, Ernest (1983), The Chinese Written Character as a Medium for Poetry, City Lights books, San Francisco, California.

Feu, V. M. du (1970), "Word prosody and sentence prosody", en: Phonetica, 21, pp. 31-39.

Galtung, Johan y Nishimura, Fumiko (1983), "Structure, culture and languages. An essay conparing the Indo-European, Chinese and Japanese languages", en: Social Science Information, 22, pp. 895-925.

García Berrio, Antonio y Vera Luján, Agustín (1977), Fundamentos de Teoria Lingüistica, Comunicación, Madrid.

Hirst, D. J. (1976), "L'intonation et la double articulation du langage», en: Phonetica, 29, pp. 396-403.

- (1980), "Un modele de production de l'intonation", en: Travaux de l'Institut de Phonétique d'Aix, 7, pp. 297-315.

Huang, Xuwu (155), Shi ci qu de yanjiu, Huanlian chubanshe, Taibei.

Jakobson, R. y Halle, M. (1973), Fundamentos del lenguaje, Madrid, Ayuso.

Lamiquiz, Vidal (1983), Lingüistica Española, Publicaciones de la Universidad de Sevilla, Sevilla.

Lieberman, Ph. (1967), Intonation, perception and language, Cambridge, M.I.T. Press.

Malmberg, B. (1971), "Analyse instrumentale et structurale des faits d'accents", en: Phonétique génerale et romane, The Hague, Mouton, pp. 211-221.

Martinet, A. (1971), "Acentos y tonos», en: La lingüistica sincrónica, Madrid, Gredos, pp. 141-160.

- (1975), La lingüistica, Editorial Anagrama, Barcelona. 
Mateos, Fernando, Otegui, Miguel y Arrizabalaga, Ignacio (1977), Diccionario Español de la Lengua China, Espasa-Calpe, Madrid.

Muljačic, Z. (1974), Fonología general, Barcelona, Laia.

Rongyi ducuode zi (1971), renmin chubanshe, Beijing.

Trubetzkoy, N. (1976), Principios de fonología, Madrid, Cincel.

Universidad de Pekín (1963), Manual de Lengua China Moderna, 2 vols., Ediciones "Shangwu", Pekín.

Wong, H. (1953), "Outline of the Mandarine Phonemic System», en: Word, IX, pp. 268-276.

Yu, Shouzhen (1981), Tang shi sanbaishou xiangxi, zhonghua shuju, Beijing. 